\title{
Article \\ The Splashing of Melt upon the Impact of Water Droplets and Jets
}

\author{
Sergey E. Yakush *D, Yuli D. Chashechkin, Andrey Y. Ilinykh and Vladislav A. Usanov \\ Ishlinsky Institute for Problems in Mechanics RAS, 119526 Moscow, Russia; chakin@ipmnet.ru (Y.D.C.); \\ ilynykh@ipmnet.ru (A.Y.I.); usanovmpei@gmail.com (V.A.U.) \\ * Correspondence: yakush@ipmnet.ru; Tel.: +7-(495)-434-95-25
}

Featured Application: Nuclear safety, stratified steam explosion.

\begin{abstract}
Small-scale experimental studies of melt splashing upon the impact of water are presented here, with a focus on the fluid dynamics and thermal aspects of these interactions. Gravity-accelerated droplets and forced short-duration water jets interacted with liquid Rose's alloy superheated to 100-200 degrees above its melting point. A repeatability study was performed for better-control of the gravity fall of a droplet. The amount of perturbation on the melt surface was obtained from a video recording, and indicated the existence of three principal stages of interaction. The cases using the forced water jet demonstrated the occurrence of a cumulative jet of melt following the collapse of the cavity caused by the water impact. Also, it was shown that numerous small-diameter melt droplets were scattered by the primary impulse, and small-scale micro-eruptions were observed, which generated small but fast melt droplets at the later stages of interaction.
\end{abstract}

Keywords: splashing; melt-water interaction; droplet impact; jet impact; cumulative jet

Citation: Yakush, S.E.;

Chashechkin, Y.D.; Ilinykh, A.Y.;

Usanov, V.A. The Splashing of Melt upon the Impact of Water Droplets and Jets. Appl. Sci. 2021, 11, 909. https://doi.org/10.3390/app11030909

Received: 29 December 2020

Accepted: 18 January 2021

Published: 20 January 2021

Publisher's Note: MDPI stays neutral with regard to jurisdictional claims in published maps and institutional affiliations.

Copyright: (c) 2021 by the authors. Licensee MDPI, Basel, Switzerland. This article is an open access article distributed under the terms and conditions of the Creative Commons Attribution (CC BY) license (https:// creativecommons.org/licenses/by/ $4.0 /)$.

\section{Introduction}

Melt-water interaction is encountered in nature and in many areas of engineering, including nuclear safety, the smelting industry, volcanology, etc. The rapid phase transition that occurs upon the contact of a hot molten material with a temperature above the boiling point of a liquid coolant produces rapidly propagating pressure waves, known as steam (or vapor) explosions [1]. This is one of the major sources of danger associated with severe accidents at nuclear power plants with light water reactors where the molten core and structural materials form a metal-oxide mixture known as corium, which can flow at temperatures as high as $3000 \mathrm{~K}$ and have contact with water, either in the lower plenum of the reactor vessel or in an external water pool. In the steam explosion wave, fragmentation of the liquid melt occurs, which dramatically increases the melt-water surface area and heat transfer characteristics, thus accelerating the conversion of the thermal energy stored in the melt into the mechanical energy of the vapor expansion and coolant acceleration.

Research into the topic of steam explosion spans several decades, and the key processes governing this phenomenon have been established. In particular, it was found that for a powerful steam explosion to occur, some premixing of the coarsely fragmented melt, coolant, and vapor (which exists as a vapor film separating the melt from coolant or as a separate phase) must be present, thus creating the pre-requisites for propagation of a self-sustained steam explosion wave. When the melt is released due to a vessel breach as a jet into a deep enough water pool, this premixing occurs naturally due to the melt jet fragmentation. This is governed by various types of instability and interaction mechanisms, as demonstrated by many integral tests performed worldwide (KROTOS [2], FARO [3], TROI [4]). However, it was demonstrated recently by PULiMS and SES experiments [5] that powerful steam explosions can also occur in the stratified configuration, where the melt spreads over the bottom of a shallow enough water pool. Therefore, an important question 
arises with regard to the mechanisms governing the melt-water premixing in this seemingly stable, stratified, flow with the heavy melt layer located under an of order-of-magnitude less dense water.

A hypothesis on the possible mechanisms for the premixing was proposed in [5] on the basis of experimental observations of melt spreading prior to a steam explosion. It was observed that hot melt did not spread as a smooth layer, rather, quite intensive sporadic melt splashes were observed, which formed a dynamically existing premixing layer above the average melt surface. An idea suggested in [5] was that the melt splashes could be caused by the impact of cumulative water jets generated by the collapse of vapor bubbles in subcooled water, which were observed intermittently near the melt-water interface.

While independent confirmation of the feasibility and efficiency of this mechanism is still a matter of ongoing study (e.g., theoretical estimates of the water energy and impulse that develop upon the collapse of a hot vapor bubble in subcooled water were performed in [6]), the problem of the impact of water on the melt surface is interesting in itself, both from a fundamental and an applied point of view.

Droplet impact on a liquid surface is a classical research topic [7-9] that can be approached from the perspective of fluid dynamics, thermodynamics, and surface physics because it provides an example of a simple, yet phenomena-rich interaction. It is known that the collision of a drop with a liquid surface can involve different regimes, including floating, bouncing, coalescence or splashing [9]. A characteristic feature of the splashing regime, where the surface of the pool liquid is significantly disturbed, is the formation of a deep crater with a crown-like cylindrical liquid film ejected from its rim (e.g., [10]). Also, in this regime, the so-called Rayleigh [11] or Worthington [7,8] central jet, or a liquid column rising above the center of the crater is formed after impact (also called a cumulative jet in Russian literature). The boundaries between different regimes have been researched by many authors in terms of the primary non-dimensional parameters, the Weber number, We $=\rho u^{2} D / \sigma$, and the Froude number $\mathrm{Fr}=u^{2} / g D$, where $\rho$ and $\sigma$ are the density and surface tension of the liquid droplet, $D$ is the droplet diameter, and $u$ is the impact velocity. A large amount of experimental data indicate that droplet bouncing and coalescence occur for low Weber and Froude numbers, whereas splashing occurs at high values, see review in [12]. The total coalescence, rebound and fast partial bounce regimes of free-falling droplet interaction with the receiving liquid were studied experimentally in [13]. For high impact velocities, numerous fine droplets (spray) are formed including multiple splashes [14]. Experiments have also shown that sometimes a large bubble becomes entrapped when the crown closes at the top $[10,12]$.

In addition to finding the regime boundaries, experimental studies and numerical simulations have revealed the fine details of the droplet-pool interaction in different regimes. Cavity development in a shallow liquid pool upon droplet impact was studied numerically by the VOF method in [15] in conditions where the cavity depth was comparable to the thickness of the liquid layer. For example, in the work of [16,17], the material distribution on the cavity surface and in the crown was studied by using contrasting droplet (inkcolored) and pool (transparent) liquids. It was shown that complex net-like patterns tend to develop on the cavity surface; also, the material distribution in the central jet was shown to be highly non-uniform. Note that most of the studies were performed in isothermal conditions, with various miscible and immiscible liquids: water-water and water-oil pairs [7-17], liquid metal [18,19], and a distilled water, silicone oil and glycerine-water mixture [20], so that the densities of the impacting and receiving liquids were either identical, or did not differ substantially.

The interaction of droplets with solid surfaces is another closely related area that focuses on drop impingement, in particular with hot (i.e., the temperature is above the boiling point of the droplet liquid) surfaces. This avenue of research is mostly driven by the problems of the spray cooling of surfaces, heat treatment of alloys and other engineering applications [21]. Of particular interest are the effects of surface wettability [22], heat transfer characteristics and the effects of surface texturing [23,24]. It was found that droplet 
disintegration into fine spray is governed either by fluid dynamic mechanisms, or by bubble formation upon contact with an overheated surface. Note that in all similar studies, only one fluid is involved, and therefore, the spray measurements were performed for the droplets of impacting liquid.

Analysis of the literature on droplet impingement shows that little attention has been paid so far to the interaction of liquid droplets with a pool comprised of another liquid with a significantly different temperature and density. There is a gap between the studies on liquid splashing, which are mostly performed under isothermal conditions and for density ratios that are close to unity, and studies on droplet impingement on overheated solid surfaces. However, for the research mentioned above (the formation of a premixed zone as a pre-requisite for stratified steam explosion), of particular interest is the splashing of a heavy, high-temperature melt that occurs upon the impingement of another liquid with a boiling temperature below the melt temperature. This problem cannot be reduced to either of the two cases, and it requires special studies.

The current work aims at filling this knowledge gap by presenting the experimental results for the splashing of melt caused by the impact of a more volatile liquid. Melt splashing was studied at the laboratory scale by dropping small ( $1 \mathrm{~mL}$ or less) water volumes (either as free-falling drops, or forced short-duration jets) on the surface of molten Rose's alloy. The characteristic density ratio between the impacting and pool liquids is about 1:9, which cannot be reproduced in isothermal experiments (water-water, water-oil etc.) or with cryogenic liquids (freon, liquid nitrogen, etc.) interacting with water. Note also that such separate-effect experiments are useful for revealing the fine, fundamental details of the interactions, which remain obscured or unclear in larger-scale integral tests, like [5].

\section{Experimental Setup}

The experiments were setup in a laboratory that is part of the GFK facility operated in IPMech RAS. This facility has been used before to perform numerous high-resolution tests on water-water and water-oil interactions under isothermal conditions [13,14], including studies on the material redistribution of the droplet and receiving (target) liquid [16,17], as well as on the acoustic effects and high-speed streamers that develop due to the droplet impact [25]. In the current work, the facility was modified so that it was able to handle hightemperature materials. The experimental setup is presented in Figure 1. The molten Rose's alloy was used as the working high-temperature fluid; its properties are listed in Table 1. The alloy was melted in a cylindrical vessel of $84 \mathrm{~mm}$ diameter and $23 \mathrm{~mm}$ height, which was heated electrically from below by a $2 \mathrm{~kW}$ heater. The melt was heated to temperatures of 200-300 ${ }^{\circ} \mathrm{C}$, which superheated it to 100-200 degrees above its melting point, as well as above the normal boiling point of water (because the latter two temperatures are quite close, see Table 1).

Water delivery was performed in two ways. The first was as a droplet falling under gravity from a fixed height of $0.58 \mathrm{~m}$. This height was chosen because previous isothermal tests have shown that the height of the cumulative jet was the highest; the higher initial positions of the droplet were not used in the experiments because the droplet became unstable and fragmented prior to impacting the surface. Smaller heights were also discarded because the impact of the droplet on the heavy melt was too weak to cause any significant perturbations. The droplets were formed by slow water delivery from a thin syringe needle; the droplet was of a nearly-spherical shape due to the effect of surface tension, and grew to a diameter of $4.2 \mathrm{~mm}$, after which it detached naturally from the needle without any initial velocity. The free-fall velocity for the above height was $\sqrt{2 g h}=3.37 \mathrm{~m} / \mathrm{s}$, and the water volume was $0.0388 \mathrm{~mL}$. 


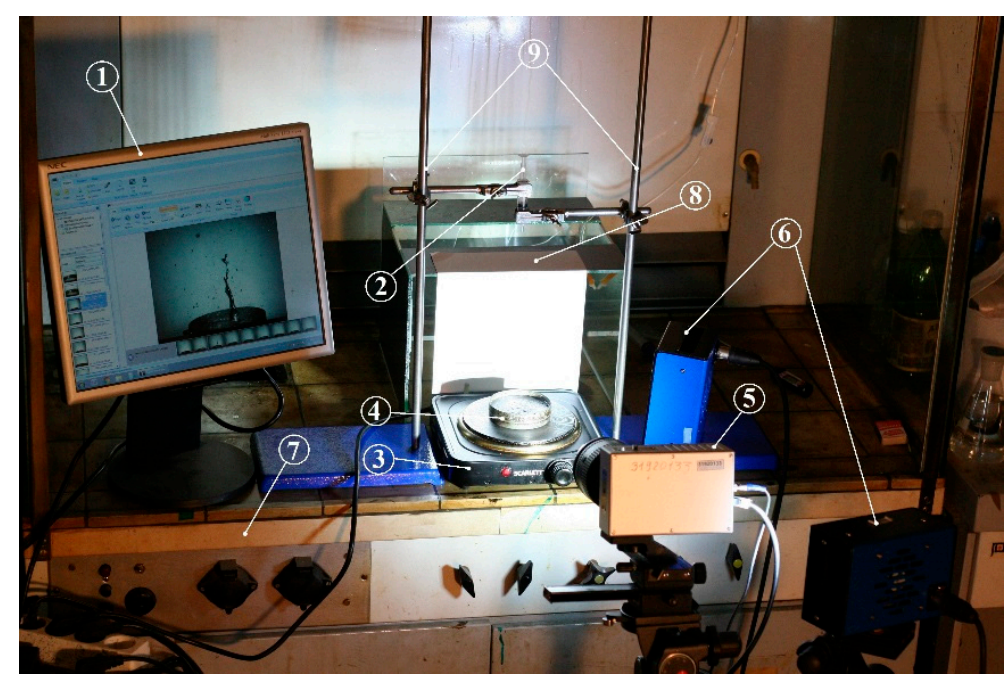

Figure 1. Experimental facility: 1-computer, 2-injector, 3-heater, 4-reservoir, 5-camera Optronis CR3000x2, 6-light sources, 7-fume hood, 8-screens, 9-tripods.

Table 1. Properties of Rose's alloy [26,27].

\begin{tabular}{cc}
\hline Property & Value \\
\hline Composition & $\mathrm{Sn}-25 \%, \mathrm{~Pb}-25 \%, \mathrm{Bi}-50 \%$ \\
Melting temperature & $94{ }^{\circ} \mathrm{C}$ \\
Density & $9720 \mathrm{~kg} / \mathrm{m}^{3}$ \\
Specific heat capacity & $0.147 \mathrm{~kJ} /(\mathrm{kg} \cdot \mathrm{K})$ \\
Thermal conductivity & $16.3 \mathrm{~W} /(\mathrm{m} \cdot \mathrm{K})$ \\
Surface tension & $410 \mathrm{mN} / \mathrm{m}$ \\
\hline
\end{tabular}

The second type of water delivery was from a syringe with the needle removed; the nozzle diameter was $0.3 \mathrm{~cm}$. In this case, water was delivered from a small height (about $100 \mathrm{~mm}$ above the surface), thus forming a forced short-duration jet. Delivery from larger heights resulted in significant jet fragmentation, so that water reached the surface almost as a spray rather than a coherent jet. The water velocity prior to the impact was in the range of $3-11 \mathrm{~m} / \mathrm{s}$, the volume of water was controlled and set to $1 \mathrm{~mL}$.

Video recording was performed using an Optronis CR3000x2 camera at the frame rate of $5000 \mathrm{fps}$ for water droplets and $3000 \mathrm{fps}$ for water jets. The camera was located at a distance of 25 to $75 \mathrm{~cm}$ from the impact point, its line of view was inclined at an angle of 5 to 15 degrees with respect to the melt surface. All experiments were recorded at a fixed resolution of $800 \times 600$ pixels in the horizontal and vertical directions. Selected video frames are presented in the following sections; these were taken directly from the video sequence, without any scaling, cropping etc. The length scale for each video sequence was determined by placing a test object (medical syringe needle of $0.8 \mathrm{~mm}$ diameter and $40 \mathrm{~mm}$ length) above the expected impact point prior to the release of the water. The frames where the test object was visible were used to calibrate the spatial coordinates in Autodesk AutoCAD 2020 software, after which the frames with the interaction were processed.

The impact velocity was obtained from the measurements of droplet (or impulse jet) leading point coordinates on the video frames immediately preceding the water-melt contact. The purpose of the experiments performed was to establish the ability of the impact of the water jet or droplet to cause noticeable perturbations and splashes of the heavier hot liquid, as well as to look for the specific effects resulting from the phase transitions and evaporation of a more volatile liquid. 


\section{Results}

\subsection{Impact of the Water Droplet}

Table 2 summarizes the results from the experiments with the water droplet falling on the molten Rose's alloy surface. The droplet volume was very well controlled by the experimental procedure of droplet generation, however, perturbations that developed during the droplet's fall in the air resulted in distortion of its spherical shape, and some scatter was observed in the impact velocities. The pre-impact droplet size indicated in Table 2 was measured as the horizontal droplet size visible on the last frame before the droplet's contact with the melt surface.

Table 2. Parameters of free-falling droplet impact experiments.

\begin{tabular}{cccccc}
\hline Case & Drop Height, $\mathbf{m m}$ & Water Volume, $\mathbf{m L}$ & $\begin{array}{c}\text { Pre-Impact Droplet } \\
\text { Size, } \mathbf{~ m m}\end{array}$ & $\begin{array}{c}\text { Impact Velocity, } \mathbf{m} / \mathbf{s} \\
\text { Melt Temperature, }{ }^{\circ} \mathbf{C}\end{array}$ \\
\hline D1 & 58 & 0.0388 & 4.56 & 3.17 & 200 \\
D2 & 58 & 0.0388 & 4.45 & 3.08 & 2.9 \\
D3 & 58 & 0.0388 & 4.48 & 3.46 & 200 \\
D4 & 58 & 0.0388 & 4.38 & 3.14 & 200 \\
D5 & 58 & 0.0388 & 3.95 & 3.05 & 200 \\
D6 & 58 & 0.0388 & 4.26 & 3.24 & 200 \\
D7 & 58 & 0.0388 & 4.03 & 3.45 & 200 \\
D8 & 58 & 0.0388 & 4.04 & 3.1 & 280 \\
D9 & 58 & 0.0388 & & & \\
\hline
\end{tabular}

As the baseline case, Case D1 from Table 2 elucidates all the typical features of the interaction observed in all the free-falling droplet experiments. After the droplet touches the melt surface, it starts to disturb it so that a cavity develops, which is surrounded by a circular "crown" into which the melt material is displaced. For each frame, the visible diameter of the crown was obtained; for most of the frames, it was easily detected thanks to the high contrast between the water (looking dark) and the melt (highly reflective).

Along with the experimental photos, it is also useful to analyze the time dependence of the crown diameter, which is presented in Figure 2; the time is plotted on the logarithmic scale. Three distinct stages of cavity development can be seen in the graph, denoted by the linear pieces of the plot, and separated by points A and B where the slope of the lines changes abruptly. Note that once the cavity diameter $d(t)$ is described by a linear function in the coordinates of Figure 2, it can be represented by

$$
d(t)=d_{0} \log _{10}\left(t / t_{0}\right)+d_{1}
$$

where $d_{0}$ and $d_{1}$ are characteristic diameters, and $t_{0}$ is a characteristic time found for each stage from the best fit of the experimental data. Since the radial velocity of the crown top is $v=d r / d t$ (where $r=d / 2$ ), it follows from (1) that the cavity velocity decays proportionately to $d_{0} / t$, and the constant in the velocity decay law changes abruptly from one stage to another. The best-fit linear regression lines are shown in Figure 2 for each stage, and they will be further discussed below in comparison with other water impact experiments.

The flow corresponding to each above-mentioned stage is shown in Figure 3; the field of view in each frame is $26 \times 17.5 \mathrm{~mm}$ and the resolution is $800 \times 600$ pixels. Immediately after the droplet touches the hot melt, high-velocity water streamers are ejected from the contact zone, almost parallel to the melt surface (Figure 3a). The video record clearly shows that water boiling occurs on the water-melt interface, where small-scale bubbles are seen (Figure $3 b$ ). It is not clear from the video if a continuous vapor film is formed to completely separate water from the melt, however, liquid water definitely remains in the cavity for long time (Figure $3 c-h$ ). 


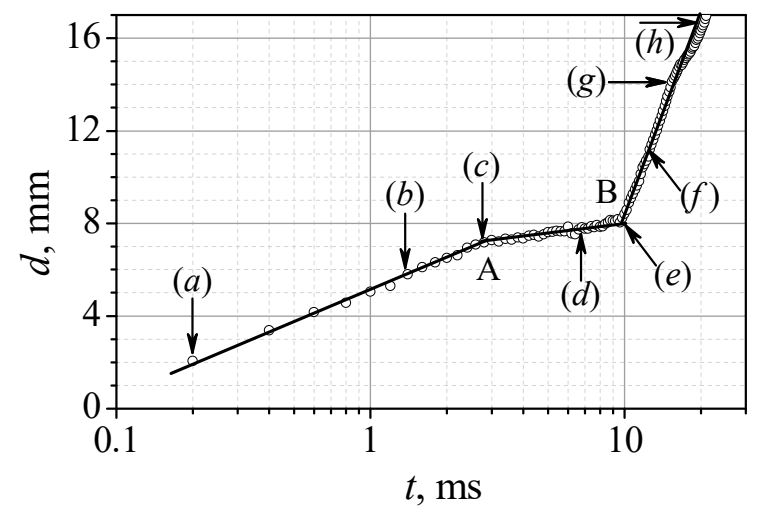

Figure 2. Time dependence of the cavity diameter (Case D1). Dots: experimental data, solid line: approximation. The arrows indicate the instances shown in Figure 3.

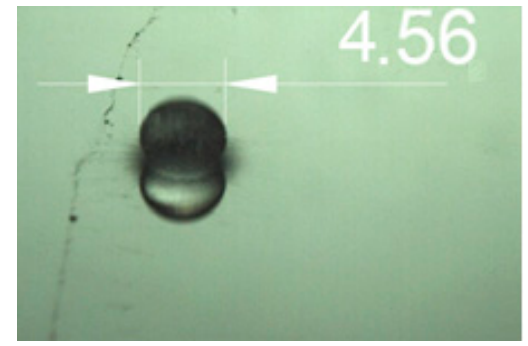

(a)

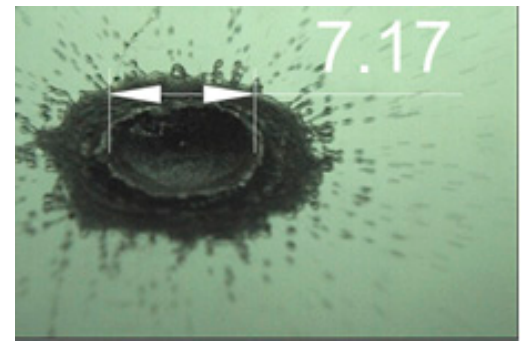

(c)

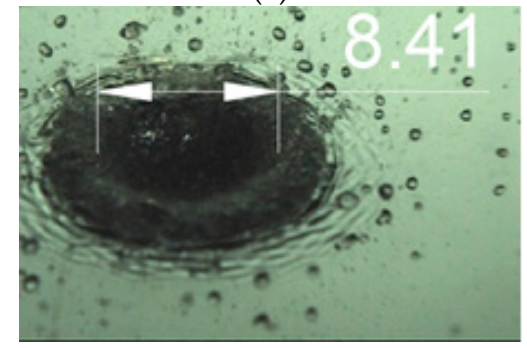

(e)

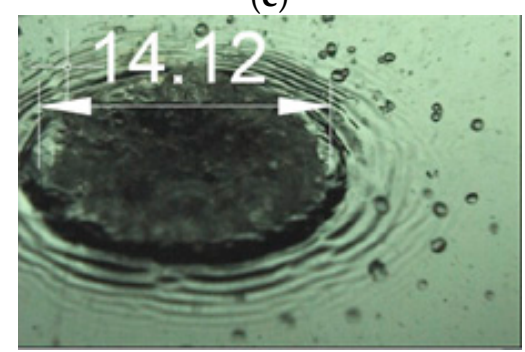

(g)

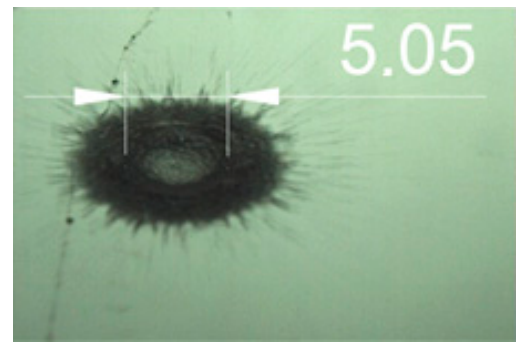

(b)

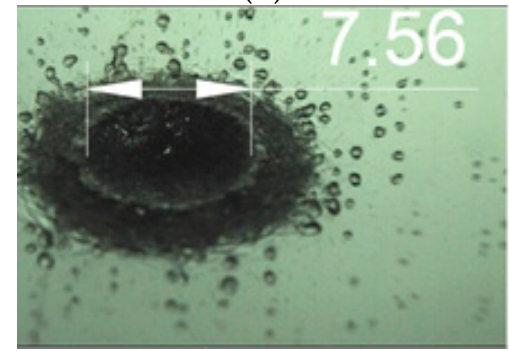

(d)

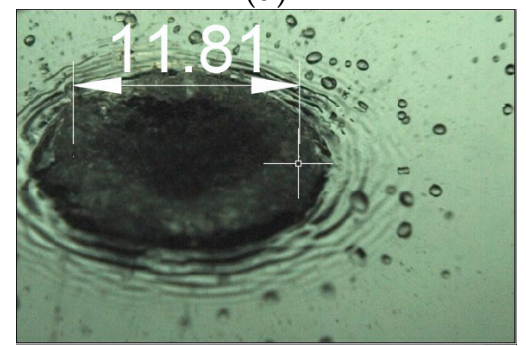

(f)

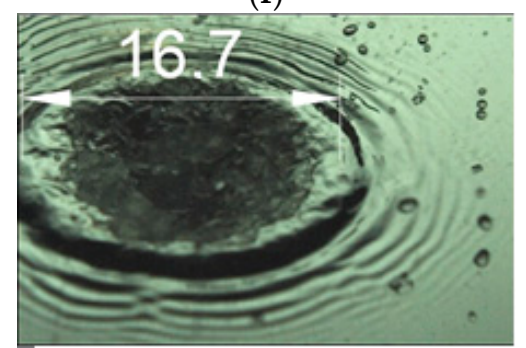

(h)

Figure 3. Snapshots of Case 1 video at the instances indicated in Figure 2 (the dimensions are in millimeters). (a) $\mathrm{t}=0 \mathrm{~ms}$; (b) $\mathrm{t}=1 \mathrm{~ms}$; (c) $\mathrm{t}=2.8 \mathrm{~ms}$; (d) $\mathrm{t}=6.2 \mathrm{~ms}$; (e) $\mathrm{t}=10 \mathrm{~ms}$; (f) $\mathrm{t}=13.2 \mathrm{~ms}$; (g) $\mathrm{t}=15.4 \mathrm{~ms} ;(\mathbf{h}) \mathrm{t}=20 \mathrm{~ms}$. 
The video frames shown in Figure 3 indicate that stage 1 of the process is mostly governed by the impact momentum gained by the melt from the droplet (Figure $3 \mathrm{a}-\mathrm{c}$ ). The cavity rapidly increases in diameter, its edge (crown) remains sharp and easily detectable in the photos. In stage 2, however, the crown edge becomes thicker (Figure 3c-e). It can be said that stage 2 corresponds to the transformation of the crown into the crest of a capillary wave propagating radially at its own speed from the place where the interaction occurred (Figure $3 \mathrm{f}-\mathrm{h}$ ). Importantly, the droplet's impact on the melt surface is insufficient for generation of the cumulative jet well that is found in water-water interactions. Obviously, this is a consequence of a much higher density ratio (higher inertia of melt in comparison with water).

As shown in Table 2, other experiments with free-falling water droplets were performed for quite similar parameters, therefore, they can be considered as a repeatability test. A summary of all experimental data is presented in Figure 4. It can be seen that, generally, the slope of the data corresponding to stages 1 and 3 follows the same trend for all of the cases D1-D9. However, the repeatability of stage 2 (the intermediate stage between the initial cavity development due to droplet impact and the surface wave propagation) is much poorer; in some cases no distinct plateau was observed so that stage 1 was gradually transformed into stage 3 .

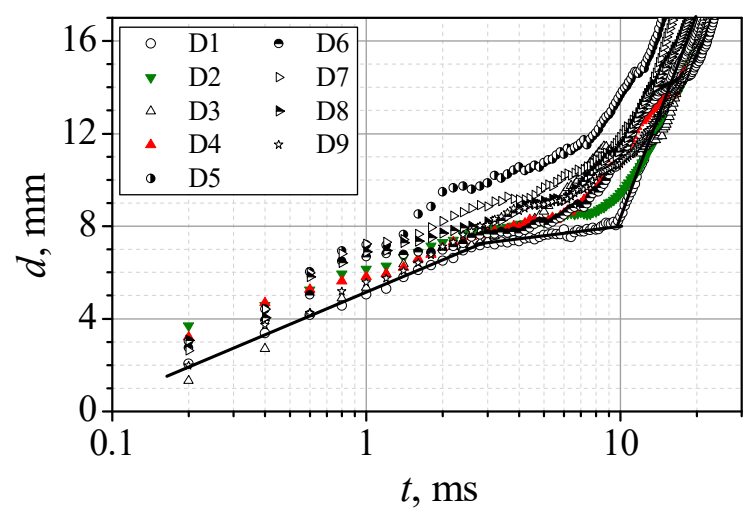

Figure 4. Summary of data obtained for free-falling drop experiments listed in Table 2. Solid lines show the approximation found for Case D1 (see Figure 2).

\subsection{Impact of Short-Duration Water Jet}

The second experimental series aimed to produce a more significant impact of water on the melt surface by releasing a short-duration jet directed vertically towards the melt surface. The parameters of the cases are summarized in Table 3. The two rightmost columns present the results obtained by processing the video records; they are discussed in more detail for each case in the following text.

Table 3. Parameters of impulse-jet impact experiments.

\begin{tabular}{|c|c|c|c|c|c|c|c|}
\hline Case & $\begin{array}{l}\text { Water Jet Diameter, } \\
\text { mm }\end{array}$ & $\begin{array}{c}\text { Water Volume, } \\
\mathrm{mL}\end{array}$ & $\begin{array}{c}\text { Impact Velocity, } \\
\mathrm{m} / \mathrm{s}\end{array}$ & Melt Temperature, & $\begin{array}{l}\text { Melt Depth, } \\
\text { mm }\end{array}$ & $\begin{array}{c}\text { Maximum Melt Rise, } \\
\text { mm }^{\mathrm{a}}\end{array}$ & $\begin{array}{c}\text { Time of Maximum } \\
\text { Rise, } \mathrm{ms}^{\text {a }}\end{array}$ \\
\hline $\mathrm{J} 1$ & 5.37 & 1 & 11 & 300 & 14 & $\begin{array}{c}>34 ;>34 ; 30.84 \\
94 \text { (est.) }^{\mathrm{b}}\end{array}$ & $\begin{array}{c}>114 ;>151 ; 163 \\
224 \text { (est.) }^{\text {b }}\end{array}$ \\
\hline $\mathrm{J} 2$ & 12.97 & 1 & 3 & 300 & 14 & 18.4 & 123 \\
\hline $\mathrm{J} 3$ & 6.69 & 1 & 4 & 300 & 14 & $51.5,38.2$ & 156,139 \\
\hline $\mathrm{J} 4$ & 7.5 & 1 & 3.6 & 300 & 14 & $73 ; 49.7 ; 20.41$ & $201 ; 168 ; 161$ \\
\hline $\mathrm{J} 5$ & 6.22 & 1 & 3.1 & 300 & 14 & $53.4 ; 44$ & $173 ; 152$ \\
\hline
\end{tabular}

${ }^{a}$ When the cumulative jet split into several parts, more than one value is given in relation to each melt part, from the upper to the lower one. ${ }^{b}$ Estimated from the camera field-of-view exit and re-entry times, assuming free motion in the gravity field.

\subsubsection{Case J1}

In this case, the jet impact is the strongest of all the studied cases due to the highest impact velocity. The main features of the interaction are presented in Figure 5, the resolution 
of each frame is $800 \times 600$ pixels, and the field of view dimensions are $60.8 \times 45.5 \mathrm{~mm}$. The camera was placed at a distance of $25 \mathrm{~cm}$ from the impact point and its line of view was inclined at 15 degrees with respect to the liquid surface. Note that the water jet approaching the melt surface is not of simple geometry; it consists of a compact leading volume followed by a thinner tail, see Figure 5a. Accordingly, the crown formed due to the impact was asymmetric. Numerous melt droplets of 1-2 mm diameter was scattered by the splashing, thus detaching from the rising crown. In Figure $5 b$, the shape of the crown, as well as a few clearly visible melt drops are shown at the instant that the crown reached its maximum height.

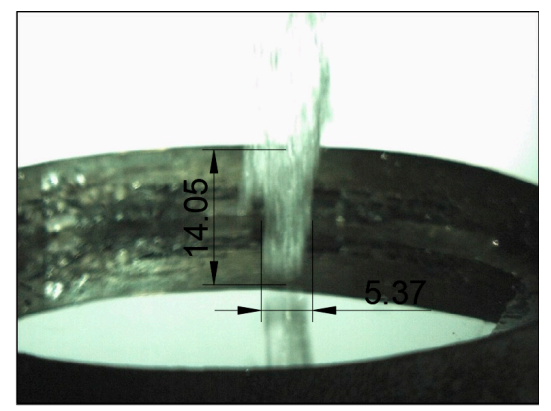

(a)

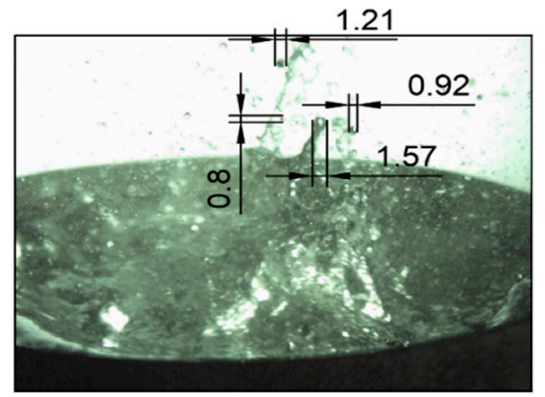

(c)

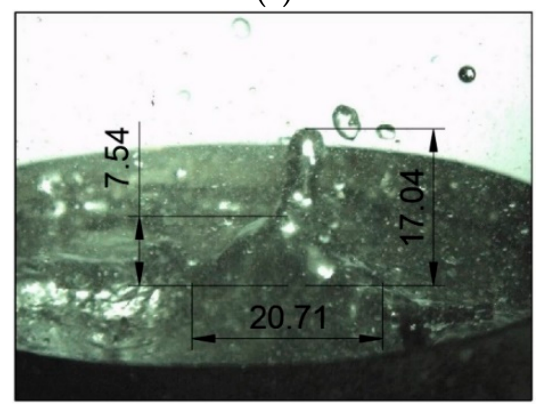

(e)

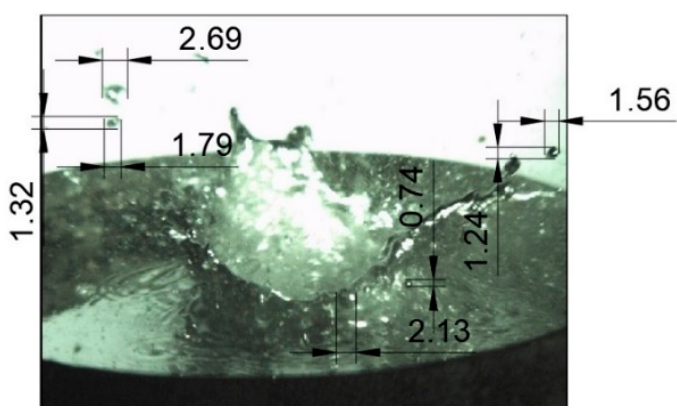

(b)

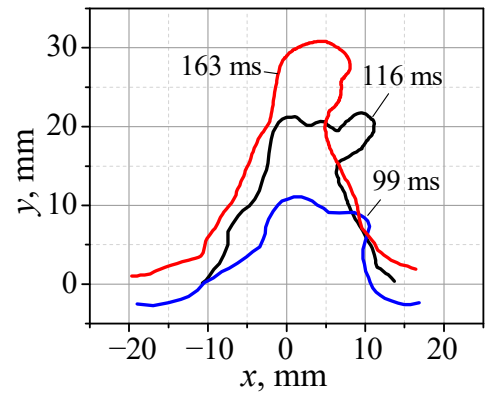

(d)

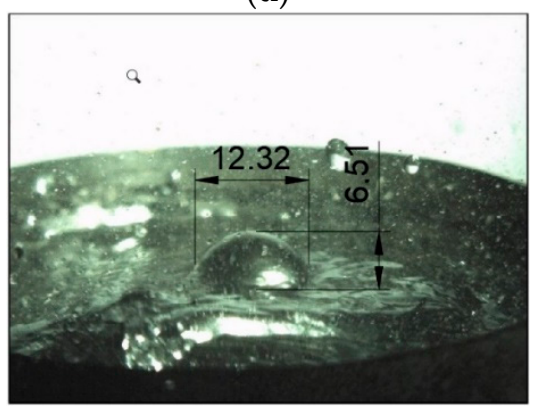

(f)

Figure 5. Melt-water jet interaction, Case J1: (a) pre-impact shape of water jet; (b) shape of the melt crown and droplets, $\mathrm{t}=18 \mathrm{~ms}$ after the impact; (c) cumulative jet and droplet shedding; (d) visible shape of the primary cumulative jet at different times; (e) secondary cumulative jet at the instant of its maximum rise, $\mathrm{t}=339 \mathrm{~ms}$; (f) bubble floating on the melt surface.

Unlike the weak disturbance caused by the free falling droplet, the perturbation of melt in this case was strong enough for the cumulative jet to appear as the result of cavity collapse. Moreover, the rising cumulative jet was fragmented into three distinct melt volumes. At $112.5 \mathrm{~ms}$, a rather large drop-shaped volume detached from the leading edge of the rising jet, and it left the field of view by $114 \mathrm{~ms}$. Then, another jet fragmentation occurred, with a melt volume that had an elongated shape with a longitudinal size of about $15 \mathrm{~mm}$, which detached at $135 \mathrm{~ms}$ and disappeared from view at $151 \mathrm{~ms}$. At $204 \mathrm{~ms}$, the latter detached part of the jet returned to the camera field of view to impact the melt surface 
at $267 \mathrm{~ms}$. At $333 \mathrm{~ms}$, the first detached melt fragment re-entered the camera view to fall on the melt surface at $368 \mathrm{~ms}$.

In the experiment, the camera was placed quite close to the impact point (at a distance of $25 \mathrm{~cm}$ ), so that its field of view was insufficiently wide to record the first and second detached melt volumes; these left the image upper boundary quite quickly. In Table 3, the rise in height for the first two parts is shown as ">32 mm", which indicates the height of the upper boundary of the camera field of view. Also, the rising times of these two parts are shown as the times when they left the camera field of view. However, taking the above exit and re-entry times, and assuming the free-space motion in the gravity field, we can obtain the following estimates: since the first detached part was absent from view during the time $\Delta t=333-114=219 \mathrm{~ms}$. Based on the scholarly solution for an object thrown upwards and caught at the same height, we can estimate the velocity of the fragment to be $v_{0}=\frac{1}{2} g \Delta t \approx 1.07 \mathrm{~m} / \mathrm{s}$. The directly measured (by the video records) velocity of the melt fragment just before it left the field of view was slightly lower, $v_{0}=0.99 \mathrm{~m} / \mathrm{s}$. Therefore, the maximum rise in height is $\Delta h=v_{0}^{2} / 2 g \approx 50.0-58.3 \mathrm{~mm}$. Adding the height of the camera view field top boundary above the melt level $(34 \mathrm{~mm})$, we can estimate that the melt rise height can reach about $84-92 \mathrm{~mm}$. Similar estimates for the second detached melt fragment gave a velocity of $0.26 \mathrm{~m} / \mathrm{s}$ and its rise in height was about $38 \mathrm{~mm}$ above the melt level.

Only the third, slowest, part of the cumulative jet was therefore recorded completely and this is presented in Figure 5c. The maximum height of the cumulative jet part was $32 \mathrm{~mm}$, its diameter at the base (melt level) was $30.8 \mathrm{~mm}$. Numerous melt droplets detaching from the jet during its rise were observed, moving upwards with velocities of about $1.2-1.9 \mathrm{~m} / \mathrm{s}$.

Following the primary cumulative melt jet, a secondary one emerged with a maximum height $17 \mathrm{~mm}$ and the diameter near its base was $20.7 \mathrm{~mm}$. After it went down due to gravity, a melt bubble of $6.5 \times 12.3 \mathrm{~mm}$ size (most probably filled with water vapor or entrapped air) remained floating on the molten metal surface for a long enough time of $0.13 \mathrm{~s}$.

\subsubsection{Case $\mathrm{J} 2$}

In this case, the impacting water volume is quite compact, measured $9.7 \times 13 \mathrm{~mm}$, and resembled a big droplet of irregular shape rather than a jet; the pre-impact velocity $(3 \mathrm{~m} / \mathrm{s})$ resembled that of the free-falling droplets in the previous series of experiments, however, the water volume was bigger. The most noteworthy features of the interaction are presented in Figure 6; the camera position and frame dimensions are the same as for Case J1.

The pre-impact shape of the water volume is shown in Figure 6a. Its impact on the melt surface results in the formation of a cavity, as well as of a crown of moderate height, no scattering of melt droplets was observed at this stage. Following the impact, some sort of cumulative jet appeared, in Figure 6b, the shape of this "jet" is shown at the time of its mid-rise and maximum rise. It can be seen that the cumulative "jet" is rather thick and slow (its maximum height is $18.4 \mathrm{~mm}$, while its base diameter is $32 \mathrm{~mm}$ ), which can indicate the presence of a gas bubble inside it. Indeed, after the disappearance of the cumulative jet, a bubble remained floating on the melt surface for $0.167 \mathrm{~s}$, see Figure $6 \mathrm{c}$.

An interesting feature of the melt-water interaction observed in this case was the sporadic appearance of mini-splashes, which can be the result of micro-bursts of water droplets entrapped by the melt at the earlier interaction stage. These mini-splashes looked like tiny cumulative jets and they produce what visually can be characterized as "microeruptions" that eject about $0.8-1.5 \mathrm{~mm}$ diameter melt droplets with characteristic velocities of about 1.21-1.52 m/s. One such micro-eruption can be seen clearly to the left of the big bubble in Figure 6c, and many more can be seen in Figure $6 \mathrm{~d}$ where the melt surface after the bubble collapse is shown. 


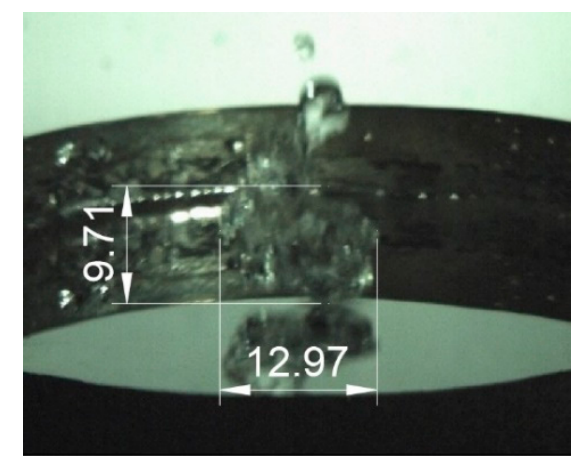

(a)

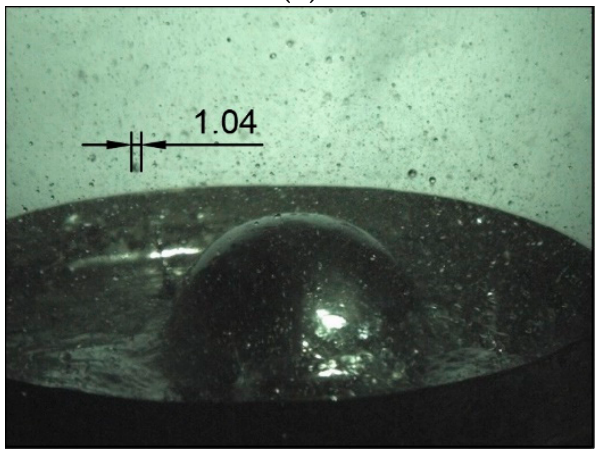

(c)

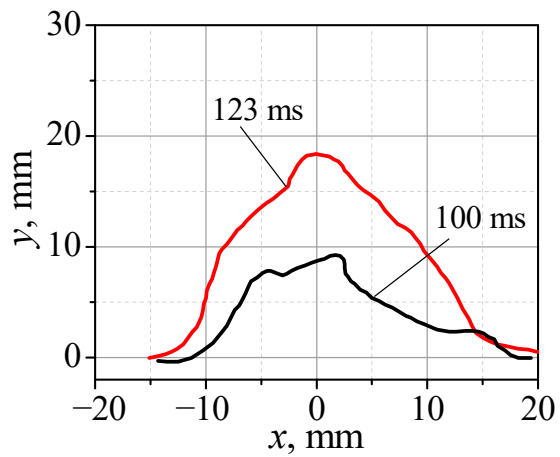

(b)

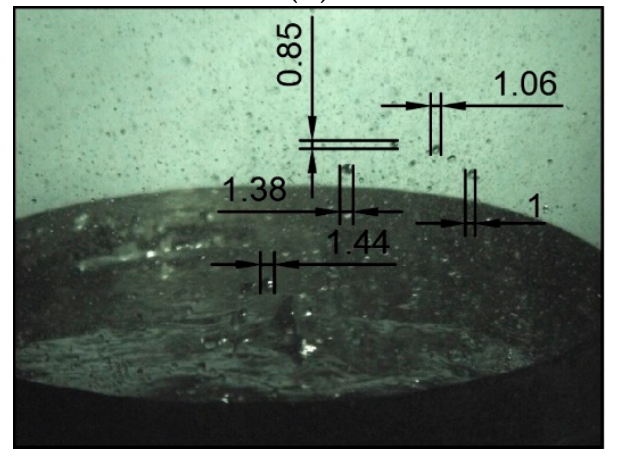

(d)

Figure 6. Melt-water jet interaction, Case J2: (a) pre-impact shape of water volume; (b) shape of the primary cumulative jet at different times; (c) floating bubble on the melt surface; (d) emergence of small "eruptions" ejecting melt droplets after collapse of the floating bubble.

\subsubsection{Case J3}

In this experiment, the impact is provided by a rather thin water jet with a compact leading volume of $6.7 \times 14 \mathrm{~mm}$, followed by a long water tail of $3.2 \mathrm{~mm}$ diameter. The interaction features are summarized in Figure 7. In order to record the whole evolution of the melt splash, the camera was placed further away from the test vessel, at a distance of $73 \mathrm{~cm}$, thus providing a $141.4 \times 106 \mathrm{~mm}$ field of view. The line of view was inclined by 5 degrees with respect to the melt surface (experiments J4 and J5 were also performed with this camera position).

The melt-water interaction in this case was rather intensive, leading to the formation of a cavity, its collapse and the ejection of a thin, tall cumulative jet, see Figure $7 \mathrm{~b}$. This process was accompanied by the formation of a large number of $0.91-2.69 \mathrm{~mm}$ diameter melt droplets, moving upwards with velocities ranging from 0.56 to $1.27 \mathrm{~m} / \mathrm{s}$, see Figure $7 \mathrm{c}$, d. It can be seen, the cumulative jet fragmented into a number of isolated melt volumes, which fell back into the melt and caused secondary melt streamers, as can be seen clearly in Figure 7e,f.

\subsubsection{Case J4, J5}

These cases were generally similar to case J3 in that the cumulative jet appeared to have a tree-like shape. Therefore, for these two cases only the visible shapes of the jet are presented in Figure 8a,b. It can be seen that the splashes of melt following the water impact reach about $5 \mathrm{~cm}$, the height of the splashes observed in the experiments with melt-water interactions where powerful steam explosions were observed [5]. 


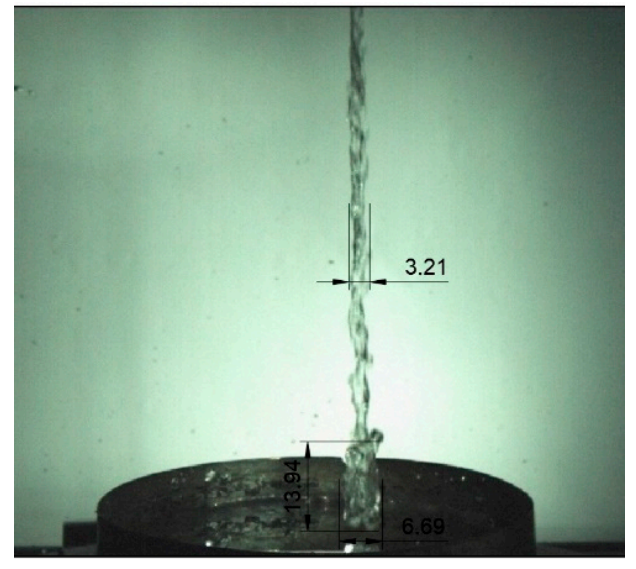

(a)

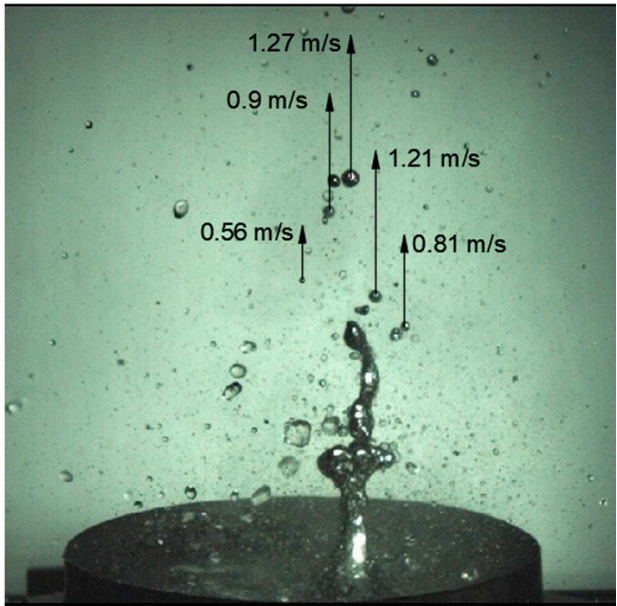

(c)

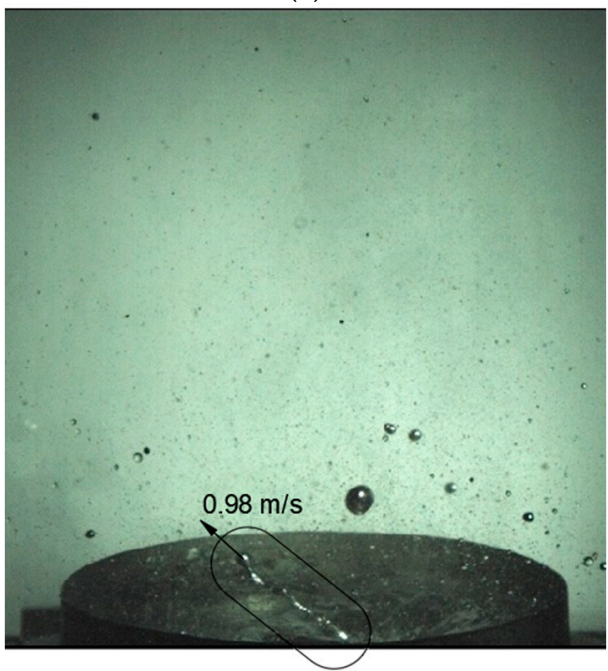

(e)

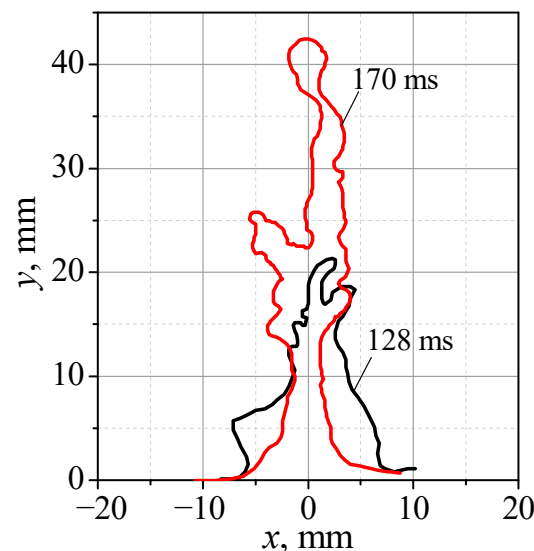

(b)

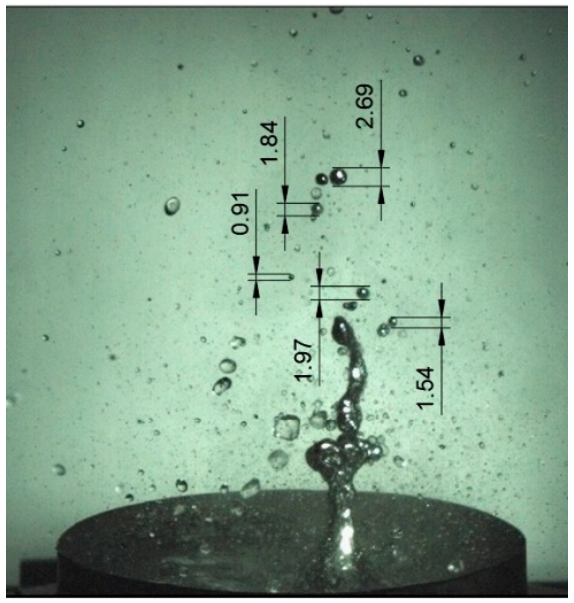

(d)

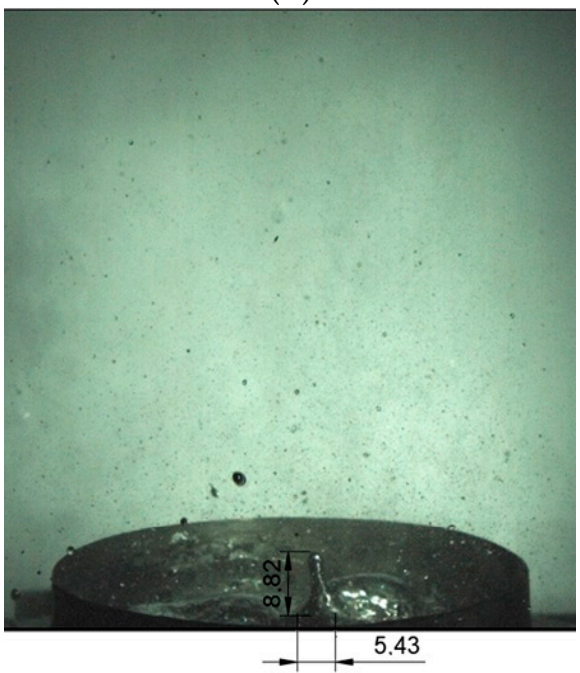

(f)

Figure 7. Melt-water jet interaction, Case J3: (a) pre-impact shape of water jet; (b) shape of the primary cumulative jet at different times; (c), (d) melt droplets generated with the cumulative jet; (e) a streamer with a melt droplet; (f) floating bubble on the melt surface with melt streamer. 


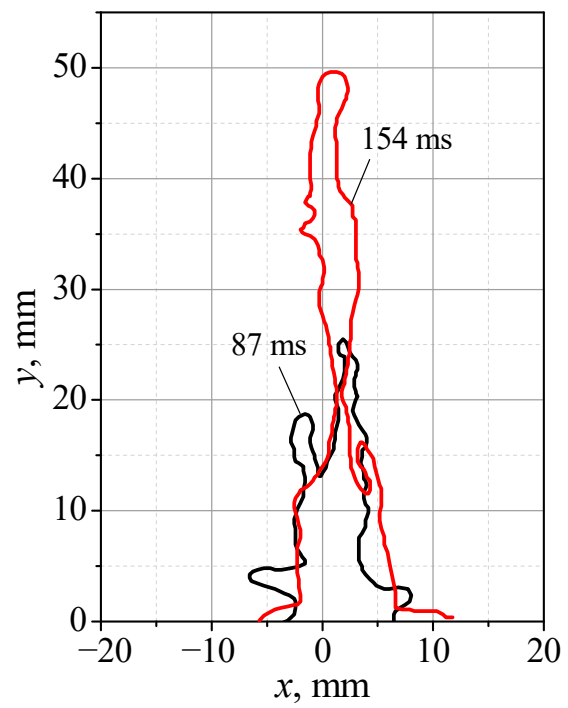

(a)

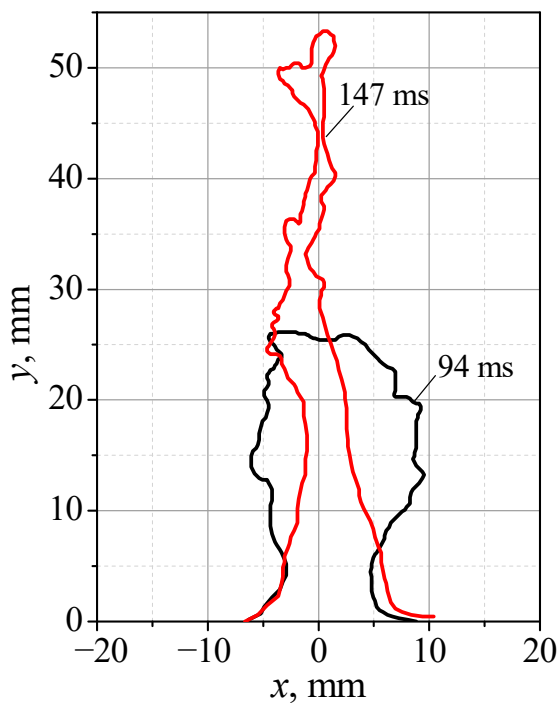

(b)

Figure 8. Melt-water jet interaction, Cases J4 (a) and J5 (b): shape of the cumulative jet at different times.

\section{Discussion}

In all the cases where water impacted on the melt surface, cavity development on the melt surface was observed, followed by the propagation of a radial surface wave at the later stage of interaction. It is interesting to compare the cavity growth features in the cases of droplet and impulse jet impacts.

In Figure 9, the time dependencies of the cavern diameter are plotted for the cases J1 and J2, together with the data from Figure 2 for the free-falling droplet impact (Case D1). It can be seen that the data from Case J1 follow the three-stage sequence that was clearly seen in Figure 2. However, case J2 shows more irregular behavior, most probably due to the bubble formation under the melt surface caused by the evaporation of water captured by melt.

Table 4. Best-fit approximation parameters (see Equation (1)).

\begin{tabular}{ccc}
\hline Case & D1 & J1 \\
\hline & Stage 1 & $0 \leq t \leq 2$ \\
\hline Time interval, ms & $0 \leq t \leq 2.745$ & 8.297 \\
$d_{0}, \mathrm{~mm}$ & 4.519 & 0.1 \\
$t_{0}, \mathrm{~ms}$ & 0.073 & 0 \\
$d_{1}, \mathrm{~mm}$ & 0 & $2 \leq t \leq 3.72$ \\
& Stage 2 & 5.626 \\
\hline$t_{0}, \mathrm{~ms}$ & $2.745 \leq t \leq 9.65$ & 2.0 \\
$d_{1}, \mathrm{~mm}$ & 1.769 & 10.862 \\
\hline Time interval, ms & 2.745 & \\
\hline$d_{0}, \mathrm{~mm}$ & 7.112 & $>3.72$ \\
$d_{0}, \mathrm{~mm}$ & Stage 3 & 25.611 \\
$t_{0}, \mathrm{~ms}$ & $t>9.65$ & 3.72 \\
$d_{1}, \mathrm{~mm}$ & 26.750 & 12.366
\end{tabular}




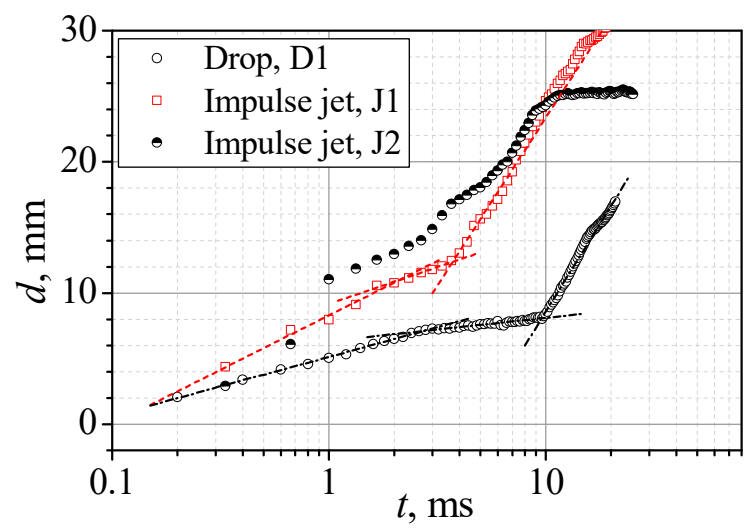

Figure 9. Time history of the cavity diameters for cases D1, J1, and J2. The dashed lines show the approximations (1) for each stage, see parameters in Table 4.

The parameters of the best-fit approximation (1) for cases D1 and J1 are listed in Table 4. In Figure 9, the approximations (1) are plotted for each stage by the dashed (for J1) and dashed-dotted (for D1) lines; the line segments are deliberately extended beyond the limiting points of the stages to highlight the intersection points where the slope changes abruptly. It can be seen that Stage 3 (surface wave propagation) is only weakly dependent on the interaction details (the slope $d_{0}$ coincides in Stage 3 in D1 and J1 within $4 \%$, that is, 26.750 vs. 25.611 , despite the significant differences in the water mass and velocity). However, the cavity edge velocity in Stages 1 is very different, and significant differences are observed in the duration of Stages 1 and 2. Generally, the data presented in Figure 9 suggests the idea of possible cavern growth regime similarity, but further experimental and theoretical studies are needed to find the governing similarity laws.

A very interesting feature of the melt-water interaction that was observed experimentally is that not only water was scattered around the impact point in the form of small droplets, but noticeable amounts of melt particles (frozen droplets) also collected around the vessel after each test, see Figure 10. At this stage, no fractional analysis of the dispersed melt was performed because it was beyond the objectives of the current work. However, it can be said that the particles scattered by the interactions are in the $\mathrm{mm}$, or sub-mm range. It remains to be seen how this dispersed fraction of melt depends on its superheat and properties, as well as how sensitive it is to the melt material and water impact characteristics.

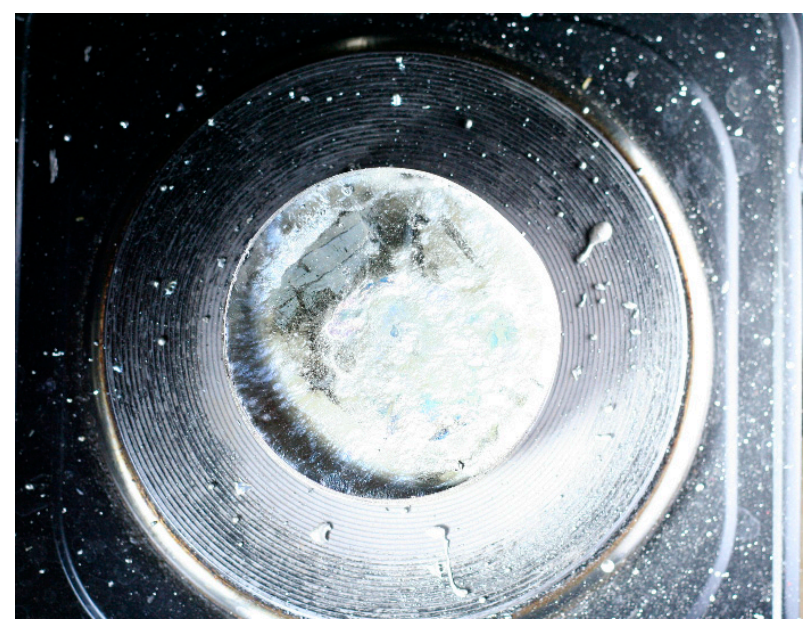

Figure 10. After-test photo of the heater and vessel with scattered frozen melt particles.

It is helpful to compare the results obtained with those available in the literature for droplets impinging on a liquid surface where both liquids are identical (i.e., the pool 
to droplet liquid density ratio is 1). As noted above, the non-dimensional parameters commonly used to analyze the regime boundaries are the Weber and Froude numbers (see review in [10]). When there is a big disparity in the properties of the impacting and receiving liquids, proper definition of these numbers become somewhat difficult. The Weber number characterizes the droplet stability due to surface tension effects, and it is logical to define it in terms of water properties; on the other hand, surface tension can also influence the melt flow. As a result, two Weber numbers can be introduced, $\mathrm{We}_{k}=\rho_{k} u^{2} D / \sigma_{k}$, where the subscript $k=w$ denotes water, and $k=m$ denotes melt. The Froude number Fr $=u^{2} / g D$ characterizes the gravity effects and it is more relevant to the flow of the heavier liquid (melt). This number contains no fluid properties; however, it can be argued that the velocity $u$ in the nominator must be the characteristic velocity acquired by the melt upon impact of water. In the case where the droplet and the receiving liquid possess identical or close densities, this velocity can be taken as equal to that of the impacting droplet; however, when the melt-water density ratio is as high as 9:1, it can be expected that the melt velocity is lower than the impact one. Proper scaling of these velocities is not known at present and should be the subject of special studies, both experimental and numerical.

To elucidate the differences between the melt-water and water-water interactions, we present the values of the non-dimensional parameters (evaluated for water properties $\rho_{w}=10^{3} \mathrm{~kg} / \mathrm{m}^{3}, \sigma_{w}=72.8 \mathrm{mN} / \mathrm{m}$, and melt properties from Table 1). For the cases D1-D9 (see Table 2) the calculated ranges are $\mathrm{We}_{w}=517-720, \mathrm{We}_{m}=893-1243, \mathrm{Fr}=191-288$. For water-water interactions, the experiments generalized in [10] show that the lower boundary of the regime where a thick central jet is formed with a detaching droplet at its top, is described by $\mathrm{We}=63.1 \cdot \mathrm{Fr}^{0.257}$ (see Figure $8 \mathrm{a}$, page 506 in [10]). The above range of Froude numbers corresponds to We $=243-270$, which is well below both $\mathrm{We}_{w}$ and $\mathrm{We}_{m}$ quoted above. As was shown in the current experiments (see Section 3.1), the perturbations of the melt surface caused by the impact of free-falling droplets were rather weak, and despite the high Weber and Froude numbers, no central jet was registered in any of the cases, D1-D9.

For the cases with jet impact, the corresponding non-dimensional parameters are listed in Table 5, together with the calculated boundary values of the thick central jet [10]. It can be seen that, generally, the experimental conditions correspond to high Weber and Froude numbers, well above the boundary $\mathrm{We}=63.1 \cdot \mathrm{Fr}^{0.257}$ obtained for the water-water interactions. Nevertheless, in Case J2 the impact was not strong enough to cause the formation of the central melt jet; a floating bubble was obtained instead (see Section 3.2).

Table 5. Non-dimensional parameters of the jet impact experiments.

\begin{tabular}{cccccccc}
\hline Case & $\boldsymbol{D}, \mathbf{m m}$ & $\boldsymbol{u}, \mathbf{m} / \mathbf{s}$ & $\mathbf{W e}_{\boldsymbol{w}}$ & $\mathbf{W e}_{\boldsymbol{m}}$ & $\mathbf{F r}$ & $\mathbf{W e}=63.1 \cdot \mathbf{F r}^{0.257}$ & Central Jet \\
\hline $\mathrm{J} 1$ & 5.37 & 11 & 8925 & 15404 & 2297 & 461.1507 & + \\
$\mathrm{J} 2$ & 12.97 & 3 & 1603 & 2767 & 70.7 & 188.532 & - \\
$\mathrm{J} 3$ & 6.69 & 4 & 1470 & 2537 & 243.8 & 259.1163 & + \\
$\mathrm{J} 4$ & 7.5 & 3.6 & 1335 & 2304 & 176.1 & 238.3522 & + \\
$\mathrm{J} 5$ & 6.22 & 3.1 & 821 & 1417 & 157.5 & 231.5934 & + \\
\hline
\end{tabular}

\section{Conclusions}

The experimental results presented in this paper confirmed that the impact of water jets with velocities of a few meters per second (the highest velocity in the experiments was $11.4 \mathrm{~m} / \mathrm{s}$ ) is sufficient to produce melt splashes to heights of about $5 \mathrm{~cm}$ or more. The experiments also revealed the three-stage interaction sequence of cavity growth, which has not been reported in previous studies (see, e.g., [10] and literature quoted therein). It remains to be seen if these stages are specific to the interactions of fluids with high density ratio.

Comparison of the experimental observations regarding the central jet formation in the melt pool indicates significant quantitative differences with the water-water interactions in terms of the regime boundaries characterized by the Weber and Froude numbers. In particular, it became clear that, due to high inertia of heavy melt, more intensive impact is 
required in order to create noticeable melt splash. Further research should be devoted to the establishment of more general features of the interaction mechanism, including the scaling, which must take into account the density ratio of the pool and impacting liquids. To this end, studies must be carried out for different melt superheats, as well as a wider range of water mass and impact velocity, in order to derive relevant non-dimensional correlations.

The results obtained in the current paper are of interest not only from the fundamental point of view, but also as an extension of the isothermal interaction of identical fluids to the "thermal hydraulics" dimension. The characteristics of melt splashes are also important for the evaluation of the thickness and phase concentrations in the zone above the melt layer spreading in a shallow water pool, where the melt jets and droplets can mix with water, which provides the conditions for stratified steam explosions, one of the major safety issues in the nuclear power industry and metallurgy.

Author Contributions: Conceptualization, S.E.Y. and Y.D.C.; methodology, S.E.Y. and Y.D.C.; experiments, A.Y.I. and V.A.U.; data analysis, S.E.Y. and V.A.U.; writing-original draft preparation, S.E.Y. and V.A.U.; writing-review and editing, Y.D.C. and S.E.Y. All authors have read and agreed to the published version of the manuscript.

Funding: This research was funded by the Russian Science Foundation (RSF), grant number 18-19-00289.

Institutional Review Board Statement: Not applicable.

Informed Consent Statement: Not applicable.

Data Availability Statement: Data sharing not applicable.

Conflicts of Interest: The authors declare no conflict of interest. The funders had no role in the design of the study; in the collection, analyses, or interpretation of data; in the writing of the manuscript, or in the decision to publish the results.

\section{References}

1. Berthoud, G. Vapor Explosions. Annu. Rev. Fluid Mech. 2000, 32, 573-611. [CrossRef]

2. Huhtiniemi, I.; Magallon, D. Insight into steam explosions with corium melts in KROTOS. Nucl. Eng. Des. 2001, 204, 391-400. [CrossRef]

3. Magallon, D. Status and prospects of resolution of the vapour explosion issue in light water reactors. Nucl. Eng. Technol. 2009, 41, 603-616. [CrossRef]

4. Kim, J.-H.; Park, I.-K.; Hong, S.-W.; Min, B.-T.; Hong, S.-H.; Song, J.-H.; Kim, H.-D. Steam Explosion Experiments Using Nuclear Reactor Materials in the TROI Facilities. Heat Transf. Eng. 2008, 29, 748-756. [CrossRef]

5. Kudinov, P.; Grishchenko, D.; Konovalenko, A.; Karbojian, A. Premixing and steam explosion phenomena in the tests with stratified melt-coolant configuration and binary oxidic melt simulant materials. Nucl. Eng. Des. 2017, 314, 182-197. [CrossRef]

6. Melikhov, V.I.; Melikhov, O.I.; Yakush, S.E.; Le, T.C. Evaluation of energy and impulse generated by superheated steam bubble collapse in subcooled water. Nucl. Eng. Des. 2020, 366, 110753. [CrossRef]

7. Worthington, A.M. The Splash of the Drop Series "The Romance of Science"; Society for Promoting Christian Knowledge: New York, NY, USA; E. \& J.B. Young \& Co.: London, UK, 1895.

8. Worthington, A.M. A Study of Splashes; Longmans, Green, and Company: London, UK, 1908.

9. Rein, M. Phenomena of liquid drop impact on solid and liquid surfaces. Fluid Dyn. Res. 1993, 12, 61-93. [CrossRef]

10. Ray, B.; Biswas, G.; Sharma, A. Regimes during liquid drop impact on a liquid pool. J. Fluid Mech. 2015, 768, 492-523. [CrossRef]

11. Castillo-Orozco, E.; Davanlou, A.; Choudhury, P.K.; Kumar, R. Droplet impact on deep liquid pools: Rayleigh jet to formation of secondary droplets. Phys. Rev. E 2015, 92, 053022. [CrossRef] [PubMed]

12. Liow, J.L. Splash formation by spherical drops. J. Fluid Mech. 2001, 427, 73-105. [CrossRef]

13. Chashechkin, Y.D.; Ilynykh, A.Y. 2020. Total coalescence, rebound and fast partial bounce: Three kinds of interaction of free fallen drop with a target fluid. Fluid Dyn. Mater. Process. 2020, 16, 801-811. [CrossRef]

14. Chashechkin, Y.D.; Ilinykh, A.Y. Multiple emissions of splashes upon drop impact. Dokl. Phys. 2020, 65, 384-388. [CrossRef]

15. Berberović, E.; Van Hinsberg, N.P.; Jakirlić, S.; Roisman, I.V.; Tropea, C. Drop impact onto a liquid layer of finite thickness: Dynamics of the cavity evolution. Phys. Rev. E 2009, 79, 036306. [CrossRef] [PubMed]

16. Chashechkin, Y.D.; Ilinykh, A.Y. Banded structures in the distribution pattern of a drop over the surface of the host liquid. Dokl. Phys. 2018, 63, 282-287. [CrossRef]

17. Chashechkin, Y.D. Evolution of the fine structure of the matter distribution of a free-falling droplet in mixing liquids. Izvest. Atmos. Ocean. Phys. 2019, 55, 285-294. [CrossRef] 
18. Li, H.; Mei, S.; Wang, L.; Gao, Y.; Liu, J. Splashing phenomena of room temperature liquid metal droplet striking on the pool of the same liquid under ambient air environment. Int. J. Heat Fluid Flow 2014, 47, 1-8. [CrossRef]

19. Ren, D.W.; Wu, S.; Yang, J.C.; Ni, M.J. Investigation of liquid metal drop impingement on a liquid metal surface under the influence of a horizontal magnetic field. Phys. Fluids 2020, 32, 053311. [CrossRef]

20. Deng, Q.; Anilkumar, A.V.; Wang, T.G. The role of viscosity and surface tension in bubble entrapment during drop impact onto a deep liquid pool. J. Fluid Mech. 2007, 578, 119-138. [CrossRef]

21. Castanet, G.; Liénart, T.; Lemoine, F. Dynamics and temperature of droplets impacting onto a heated wall. Int. J. Heat Mass. Transf. 2009, 52, 670-679. [CrossRef]

22. Clavijo, C.E.; Crockett, J.; Maynes, D. Hydrodynamics of droplet impingement on hot surfaces of varying wettability. Int. J. Heat Mass. Transf. 2017, 108, 1714-1726. [CrossRef]

23. Moon, J.H.; Cho, M.; Lee, S.H. Dynamic wetting and heat transfer characteristics of a liquid droplet impinging on heated textured surfaces. Int. J. Heat Mass. Transf. 2016, 97, 308-317. [CrossRef]

24. Liang, G.; Mu, X.; Guo, Y.; Shen, S.; Quan, S.; Zhang, J. Contact vaporization of an impacting drop on heated surfaces. Exp. Therm. Fluid Sci. 2016, 74, 73-80. [CrossRef]

25. Chashechkin, Y.D. Fast superfine components and sound packets in flows induced by a drop impact on a target fluid at rest. Fluid Dyn. Mater. Process. (FDMP) 2020, 16, 773-800. [CrossRef]

26. Tables of Physical Quantities; Kikoin, I.K. (Ed.) Atomizdat: Moscow, Russia, 1976. (In Russian)

27. Plevachuk, Y.; Sklyarchuk, V.; Gerbeth, G.; Eckert, S.; Novakovic, R. Surface tension and density of liquid Bi-Pb, Bi-Sn and $\mathrm{Bi}-\mathrm{Pb}-\mathrm{Sn}$ eutectic alloys. Surf. Sci. 2011, 605, 1034-1042. [CrossRef] 